\title{
The promise of problem-based learning for training pre-service technology teachers
}

\author{
A Hattingh* \& R Killen \\ University of Pretoria \& University of Newcastle (Australia)
}

\begin{abstract}
This article describes a learner-centred pedagogy for training student teachers. The inquiry was guided by two questions: (1) Is problem-based learning $(P B L)$ an effective strategy when training prospective Technology teachers? (2) To what extent do student teachers transfer their own experiences of PBL to the authentic classroom situation? After exploring the cognitive dimensions and characteristics of $\mathrm{PBL}$, a rationale is provided for using PBL particularly for teacher training in Technology Education. Data collected through quantitative and qualitative methods suggest that the training was perceived as a relevant, creative and satisfying professional development learning experience. However, when having to transfer PBL competencies to real schools, the student teachers experienced uncertainty about their new roles as learning facilitators in a less structured and less predictable PBL environment.
\end{abstract}

\section{INTRODUCTION}

$\mathrm{O}$ ne of the core functions of professional education is to ensure that knowledge and skills acquired during training are transformed into the ability to apply them when and where it matters - in the workplace. In fields such as teacher education there is considerable debate about how best to achieve this goal. At one end of the spectrum there are programmes which place a very heavy emphasis on the development of foundational knowledge, with minimum opportunities being provided for practical application of that knowledge during training. At the other end of the spectrum we find programmes that are totally school-based (Schön 1987 \& Fish 1989).
This article describes an intermediate approach in which pre-service teacher education students were provided with innovative school-based experiences that were deliberately designed to enhance the transfer of knowledge from the institutional training setting to the classroom. The approach was developed and applied in South Africa, partly in response to the dramatic changes that have been occurring as a result of the restructuring of the education system following the 1994 elections.

One of the new Learning Areas in the restructured school curriculum is Technology Education. The introduction of this new Learning Area has implications for pre- and in-service teacher education (Kahn \& Volmink 1997:1), especially in the absence of an established subject called "Technology" at South African tertiary institutions. The need for exploring a suitable methodology for training student teachers for a new Learning Area anchored in a new paradigm in education (outcomes-based education) is paramount if we are serious about departing from the dominating transmission-based methodology of teaching found in most South African schools (DoE 1997).

This article describes a training methodology developed from some of the principles of problem-based learning $(P B L)$. The inquiry reported here addressed two research questions: (1) Is PBL an effective strategy when training prospective Technology teachers? (2) To what extent do student teachers transfer their own experiences of PBL to the highly demanding authentic classroom situation?

\section{CONCEPTUALISING TECHNOLOGY EDUCATION FOR A SOUTH AFRICAN CURRICULUM}

Because the term "technology" is used in many different ways, the term "technology education" (TE)

\footnotetext{
${ }^{*}$ Contact person

$\operatorname{Dr}$ A van Loggerenberg-Hattingh Dept of Curriculum Studies, University of Pretoria, 0002

Tel: $\quad$ (012) 420-2771 (w)

Tel: $\quad$ (012) 347-6561

Cell: 0829266655

e-mail: avlogger@hakuna.up.ac.za
} 
has been applied variously to applied science, technical-vocational education, industrial arts and design, computer education and information technology (Thomas 1988; Waks 1993; Herschbach 1995). Herschbach (1995) traces the etymology of the word technology and suggests that it should be considered as the reasoned application of technical knowledge. HEDCOM (1996:28-9), however, reminds us that, historically, technology has mistakenly been perceived as the acquisition of technical, motor and computer skills only. Waks (1993:i) explicitly states that modern technology involves higher-order cognitive processes in conjunction with practically based problem-solving activities. In South Africa, the following definition forms the cornerstone of TE in C2005 (DoE 1996:12-13): “(TE) concerns technological knowledge and skills, as well as technological processes, and involves understanding the impact of technology on both the individual and society". Curriculum 2005 provides very limited guidance for teachers concerning the most appropriate ways for helping students to learn about technology. It is, therefore, very important that teacher educators should be able to provide beginning teachers with the understandings and skills that will enable them to make sensible instructional choices when implementing the TE curriculum.

Since the technological process is triggered by a problem or need, Williams and Williams (1997) contend that problem-based learning is an appropriate strategy for facilitating learning in TE. Black and Atkin (1996:78) also remind us that real-life problems that feature in TE never exist in isolation and that technological activities are integrated and break down the artificial barriers between subjects. The innate nature of TE presents itself as problem-based and integrated, which in turn challenges teachers to implement constructivist, hands-on and cross-curricular approaches to teaching. A mode of transmitting factual information and a recipe-like application of algorithms when solving problems will simply not contribute towards the cultivation of innovation and problem-solving skills envisaged with TE. The next section will unpack some of the conceptual dimensions of $P B L$ that will help to validate the relevance of PBL for training student Technology teachers.

\section{PROBLEM-BASED LEARNING AND PROBLEM-SOLVING}

Problem-based learning (PBL) is an innovative approach to curriculum design and implementation that has been slowly gaining support in higher education. As early as 1960, PBL was being introduced into medical education programmes as a means of addressing major problems such as the rapid increase in information that medical students were required to assimilate, the difficulties students experienced in trying to integrate knowledge from a fragmented curriculum, and the perceived lack of critical thinking skills, problem-solving skills and interpersonal communications skills of medical graduates (Schmidt 1983, 1993; Barrows 1986; Everwijn, Bomers \& Knubben 1993). By the early 1980s, the $\mathrm{PBL}$ approach was sufficiently well researched and developed to be used as the basis for a complete undergraduate medical programme, as is the case at the universities of Newcastle (Australia), Maarstricht (The Netherlands) and McMasters (Canada) to name a few. Since then, the application of PBL in medical programmes has become relatively common and $\mathrm{PBL}$ has been applied extensively in other areas such as Architecture, Management and Leadership, BioTechnology and Engineering (Duch, Groh \& Allen 2001; Wilkerson \& Gijselaers 1996). As the popularity of PBL has increased, so too have the variations in its interpretation. Like many other concepts in education (such as outcomes-based education) there is considerable confusion about its basic tenets and frequent misuse of the term PBL.

PBL is broadly defined as a curriculum design approach where the entire curriculum content (knowledge, skills, attitudes and values) is organised around authentic problems that motivate learners to identify and research concepts and resources necessary to solve the problems (Ornstein \& Hunkins 1993. Boud \& Feletti 1997). Learners work mostly in collaborative learning teams, "bringing collective skills in acquiring, communicating and integrating information" (Duch, Groh \& Allen 2001:6). The fundamental assumption behind PBL curriculum design is that a carefully structured set of problemsolving experiences will lead learners to a deeper understanding of the subject matter than they would obtain through traditional teaching-learning experiences. Quite clearly, this result will not be achieved unless the curriculum is based on an extensive web of carefully constructed problems that are separately and collectively designed to lead the learners to the required outcomes and levels of understanding.

It is extremely unlikely that PBL of the type defined above will ever be implemented on a large scale in any public school system - it would require far too many resources and far too much retraining of teachers. However, school teachers can adapt their teaching to incorporate some of the principles and techniques of $\mathrm{PBL}$. The essential idea that learning in PBL "results from the process of working towards resolution of a problem ... (that has been) encountered first in the learning process and serves as a trigger for the application of problem-solving or reasoning skills" (Barrows \& Tamblyn 1980:2) can be applied quite readily in a non-PBL programme. The essential point is that the problems can be used as a carefully designed learning experience through which learners gain knowledge and understanding, rather than being straightforward applications of prior learning. When teachers use problems as the focal point for a section 
of the curriculum (rather than as the focal point for the whole curriculum as is the case in $\mathrm{PBL}$ ) they engage in what Killen (2000:129) refers to as "using problem-solving as a teaching strategy". This approach to teaching retains the emphasis on learning about the subject through solving problems, rather than simply learning how to solve problems by applying algorithms. Thus, it provides some of the benefits of PBL without the need for a total redesign of the curriculum.

When teachers decide to use problem-solving as a teaching strategy the most effective problems are likely to be those that adhere to the rigorous criteria for PBL problems. The problems should be authentic and credible; be relatively unstructured and openended; require seeking, accessing and evaluating information from various sources; and be complex enough to require considerable individual and collaborative effort (Claxton 1999:32; Eason \& Green 1987:243). Carefully chosen problems of this type will be interesting, challenging and engaging and have the potential to encourage and facilitate high levels of comprehension and skill development (Albanese \& Mitchell 1993)

To help their students learn effectively through problem-solving, teachers themselves need to have experienced this approach to learning. They need to have gone through the process of grappling with new ideas, testing hypotheses, developing creative solutions and experiencing the satisfaction of learning that is driven by their own quest for knowledge. This article describes a research project that provided a group of Technology teacher education students with such experiences, and then examines how they were able to transfer their personal experiences of problem-solving to real classroom situations in South Africa.

\section{AN OPPORTUNITY TO USE PROBLEM - SOLVING AS A TEACHING STRATEGY}

The training intervention described in this article occurred at a major urban university in South Africa. The subjects for the study were a group of twenty students who were enrolled in a Secondary Teacher Education programme designed to prepare them to teach in the new Technology Education Learning Area in high schools. For a six-month period of this programme, a training intervention was designed with a dual purpose. Firstly, it had to help the student teachers acquire knowledge and skills related to the Technology curriculum that they would be required to teach. Secondly, problem-solving as a teaching strategy was modeled to them since they would later be expected to teach Technology through problemsolving to real classes. After the training intervention, it was arranged for the student teachers to try to apply the new teaching strategy in schools for one month.
Full details of the programme are provided in Van Loggerenberg (2000).

For the first three months of the training intervention, the problems that were used by the lecturer to trigger the learning experience focused on the learning outcomes of Technology Education as they are defined in Curriculum 2005 (DoE 2000a). Typically, in one problem they had to investigate, design, build and demonstrate three pieces of low-cost apparatus that science learners could use in the laboratory when doing practical work. Some examples of the apparatus included a simple ripple tank for wave experiments, a hot wire ammeter, a Cartesian diver for demonstrating the transmission of pressure in liquid and a Van der Graaf generator (Whittle 1993).

During the last three months, students were required to design problem-solving tasks related to the Technology Education curriculum. During this time, prospective teachers acted as learners for one another when it was not their turn to facilitate a self-designed problem-solving task. During the last month they had to work through a problem-solving task that was the same one they would later use in real classes. For example, one problem aimed at achieving the outcomes of a) selecting and evaluating products and systems, and b) applying the technological process to solve problems and to satisfy needs and wants ethically and responsibly. It required students to solve an energy provision problem in a rural area where the National Electricity Grid cannot provide energy for household needs. After researching alternative forms of energy, the solution of producing and using biogas was proposed, because it was also beneficial for addressing the sewerage problem of a rural community and therefore environmentally friendly. The students then designed and built biogas-producing plants and a household device (eg a methane gas lamp) which they had to demonstrate working effectively.

After completing the task they were given the opportunity to scrutinise, redesign and change the problem as they wished, since they had to take ownership for it when they used the problem in their teaching practice. The only demand from the researcher was that they had to have a uniform problem-solving design and implementation plan that they could all use in the various schools in which they were placed.

The foci of all the problems that the student teachers engaged in during the training intervention were guided by four integrated sets of demands. First, the training had to be guided by the principles of outcomes-based education (Spady 1994) because this is the foundation of the educational reform process in South Africa. Second, the training had to be guided by the critical outcomes (life-long learning outcomes) defined by the South African Qualifica- 
tions Authority (SAQA 1997). Third, the training had to be guided by the Technology Learning Area outcomes provided by the Department of Education (DoE 1996). Finally, the training had to prepare the students for their future roles as technology teachers as these roles are defined in the South African Norms and Standards for Educators (DoE 2000b). The way in which these factors were balanced is described in detail in Van Loggerenberg (2000).

\section{RESEARCH DESIGN AND METHODOLOGY}

The twenty student teachers in this study were trained for three hours per week for six months as part of their methodology course before they taught real classes for one month. All participants had a BSc degree and were enrolled for the one-year full-time Diploma for Secondary School Education, which prepares them to teach from Grades 8 through 12. The one-month authentic experience was designed to provide information on the extent to which student teachers transferred their experiences of learning through problem-solving to teaching through problem-solving. Five secondary school principals agreed to have the "experiment" conducted in their schools. One principal allocated two classes, which meant that six student teachers could be accommodated in schools. Six of the twenty student teachers volunteered to do the "experiment" in the schools. These student teachers served as six case studies for in-depth study. The remaining 14 teachers taught in their second specialisation (not Technology) and were not required to use problem-solving as a teaching strategy. Altogether 102 Grade 10 learners were involved in the school intervention, which lasted for one month, with an average of three hours per week for Technology Education.

Data were gathered from both the student teachers and the school learners whom they taught. A variety of data-gathering methods was used with the aim of enhancing the trustworthiness of the data as well as to enrich the depth of understanding of the students experiences during their training and their teaching in real classes. Firstly, in-depth individual interviews were conducted and secondly, each student teacher had to keep a journal of their practical teaching experiences. Data obtained from the Grade 10 learners entailed the writing of pre- and post-knowledge tests on the curriculum content taught through problem-solving, as well as written comments about their experiences of problem-solving.

\section{RESULTS OBTAINED FROM THE TRAINEE TEACHERS}

\section{Student teachers' reports of their training experiences}

Various themes emerged from the transcribed interviews with the six student teachers pertaining to their own experiences of the training intervention. These themes were: valuable learning experience, unstructured teaching approach, learner-centred and resources-based approach, cooperative learning experience and creative learning experience. Typical comments made by student teachers will be used to illustrate their thoughts on these themes.

Four of the six student teachers interviewed experienced the intervention as a "valuable learning experience". It seemed that they contributed its value to what they perceived as the practical, hands-on nature of the problem-solving experience. "I feel that this training was very practically orientated and relevant and it is this fact that made the course successful. I have personally grown and I believe so have my fellow students". One student mentioned what was intended with the training intervention, namely to teach Technology content through problem-solving, as well as to give them exposure to teaching through problem-solving: "Yes, this was the one subject in which I have learnt the most in the whole year. Apart from learning how to design lesson presentations, I also learnt a lot about the subject that I will teach as well".

Three student teachers commented on the "learnercentred and resource-based" nature of their experience. They mentioned that problem-solving compelled them to become actively involved, to read extensively and to put extra effort into their learning. The perceived benefits of the approach were summed up well by one student's comment that: "It kept us very busy. All the extra effort I had to put in looking for relevant problem settings forced me to look beyond textbooks. I actually landed up in the Department of Biochemistry. I had some valuable discussions with lecturers there, which broadened my horizons".

Generally the student teachers reported positively on their experiences with "cooperative learning" in the PBL environment. One student commented: "Well I am glad that you divided us into groups to do the tasks. It makes a big task like this much easier and we know all the benefits of group work. We brainstorm the more ideas, the better. We share the research work amongst ourselves, and we learn how to work with fellow students".

One student teacher, who was in her 16th year of formal study, felt that the training intervention was a "creative learning experience": "At the beginning of 
the year I could not think creatively at all, because it was never necessary to be creative. Your approach has challenged me to develop my creative thinking to such an extent that I can think diversely about problems and solutions".

Not all students were comfortable with this new approach to learning, particularly since it was far less structured than their previous learning experiences. One student teacher commented: "I think at first I found it a loose approach. I am one of those people who like structure". When prompted she added: "I guess I like well-organised presentations. I don't think that all subjects can be presented like this, but it will work in a subject didactics class". One other student mentioned that he definitely "prefers lectures". Such tentative reactions were not surprising, given that all the participants had previously experienced school and university education that was typically very teacher directed (Jansen 1997; Luckett 2001).

The responses of the student teachers to this part of their problem-solving learning experiences were generally consistent with advantages and limitations of this strategy as outlined in Killen (2000). However, it is interesting that some student teachers experienced the intervention as both a professional and personal growth experience, while others were frustrated by the ill-structured nature of PBL. It was anticipated that the student teachers" personal experiences as "problem-based' learners would influence their approaches to using problem-solving as a teaching strategy.

\section{Student teachers' reports of their PBL school experiences}

After their university-based training experiences, the student teachers moved to schools to attempt to transfer their personal experiences of problem-solving to their own teaching in authentic classroom situations. Each student teacher had a "problem-solving teaching kit' consisting of the same problem-solving task, implementation plans and instructional materials and resources to enable them to use the biogas problem-solving task to teach their school learners about renewable energy. They were required to use this to guide their teaching practice. The learners had to solve the same energy-related problem with the same instructional materials and resources that the student teachers used during their university-based training. At the end of their teaching practice, the students were interviewed about the challenges they had faced and the lessons they learned from their experience in the authentic teaching situation. In general they realised that being a facilitator of learning in a less predictable learning environment such as PBL demands skill, confidence and "thinking on your feet" as one student teacher indicated. This student teacher commented that, when learners do not sit passively and quietly in rows, facilitation skills that differ from direct instruction skills are of the utmost importance: "I think if a facilitator doesn't know what he is doing it could be chaos in a big class. There is a lot of noise and the more excited they become, the louder they talk". The following comments illustrate the uncertainty some student teachers felt about their "sage on the stage to guide on the side" functions (King 1993:30). "Some of the groups were fine, but I was really worried about (others). It seemed that they lose interest if they really don't see their way out. Although we encouraged them not to lose heart. I know that I am a facilitator who is not supposed to transfer, but sometimes I felt like doing it. The easy way out will be just to tell them what they need so that they could progress".

Another student teacher commented about the frustration experienced by learners during their problem-solving endeavours and she actually articulated her own uncertainty as to how to handle the situations: "I moved in between the different groups all the time. Actually all I did was to encourage and motivate them. Although they asked me questions ... I didn't really give them any hints, because the idea is that they do the work, isn't it? Sometimes I got the idea that some individuals were very frustrated with this method". Another dimension of the uncertainty a student teacher had is reflected in the amount of feedback she had to give to learners during the problem-solving process: "It took a lot of my energy to work in this way. All the learners wanted your attention at the same time. If a cooperative group shows you their progress it was difficult for me to determine how much feedback to give them". In her journal another student teacher wrote about her uncertainty as a facilitator: "Day 1: ... instead of brainstorming and discussing it with their group members, I was showered with questions. I didn't really know whether I was supposed to answer all or some of these questions. I think some of (them) were just chancers who were too lazy to tackle the problem and wanted me to give them shortcuts, I think. I might be wrong".

\section{RESULTS OBTAINED IN SCHOOLS}

As a measure of the effectiveness of problem-solving as a teaching strategy, the student teachers administered a pre-test and a post-test to the learners in their classes. The test focused on the curriculum content that was covered by working through the problemsolving task. The pre-test was written three months prior to the school intervention and the post-test one month after the intervention. Pre- and post-tests were not identical. If learners were given exactly the same test for pre- and post-test purposes, the pre-test could have prepared the learners for the post-test to an extent. To avoid this problem, but to enable comparisons to be made, the same concepts were used in the 
tests, but they were formulated differently and also placed within a changed context. The similar conceptual questions were pitched on the same cognitive level of the Bloom taxonomy and validated by two teachers in participating schools. Student teachers did not see the pre- or the post-test to avoid them teaching for the tests. The pre-test mean score was $62 \%$ while the post-test mean score was $65 \%$. The $\mathrm{p}$ value of 0,0133 (Wilcoxon Sign Rank Sum Test) indicated that a significant increase from the pre- to the post-test was present. It can therefore be assumed that the problem-solving intervention, as facilitated by the student teachers, was responsible for a meaningful improvement in the achievement of the learners whom they taught.

After the learners wrote the post-test, they were given an opportunity to write down their experiences of the "new method' that was used to teach Technology. The following learner voices add clarity towards understanding the extent to which the student teachers successfully transferred their problem-solving experiences to the authentic classrooms. "You do not have to learn everything like a parrot. It is nice to do things and practical work on your own." "It can be of great advantage if we can use this method more often in class." "One does not just sit on your chair and write frantically like a zombie." "I really enjoy these hands-on Technology projects. It places science in a different light." "I do not like it. You waste valuable academic time, which my parents are paying for". "I did not learn very much from this project, because the topic had nothing to do with our syllabus." As might have been anticipated from other research into the use of problem-solving as a teaching strategy (Killen 2000), most, but not all, learners viewed their new experience positively.

\section{DISCUSSION}

The training intervention described in this article was designed to answer two questions: whether problemsolving was a suitable strategy for training Technology teachers and whether these teachers could transfer the strategy to authentic classrooms. The first question was answered in the affirmative although no attempt was made to demonstrate that the training was more effective than any other approach. Generally, the training was described by the teacher education students as different but valuable since it placed the responsibility for learning where it belongs - on the prospective teachers. These claims are validated by comments such as "This was the one subject in which I have learnt the most in the whole year" and "(it) was very practically orientated and relevant and it is this fact that made the course successful". This finding resonates with the findings of Tanner, Galis and Pajak (1997:10) who used PBL in a course on Advanced Preparation of Educational Leaders and found that students rated it significantly higher than their traditional course. The particular problem-based experiences of the students in the present study even impacted on one student teacher beyond the academic domain: "I have personally grown and I believe so have my fellow students". The approach also compelled the student teachers to put effort into their own information searches and creativity in order to design relevant problems and solutions. In general, the additional demands that this approach placed on the student teachers were viewed as positive learning experiences.

The second critical question enquired into whether the student teachers actually transferred new knowledge and skills to authentic classrooms. The learner achievement tests indicated that the prospective teachers were reasonably successful in their first attempt to transfer their new teaching skills to the classroom. Bearing in mind that the learners were not used to the rigorous demands of active involvement and accountability conferred upon them by learning through problem-solving, the modest, but significant, gains in their knowledge were encouraging.

One of the most frequently mentioned barriers to implementing $\mathrm{PBL}$ curricula is the pressure for content-coverage, which sparks off the debate on breath or depth of content. Central to the debate is the assumption that learners learn less information if they are exposed to learning through problem-solving (Gallagher \& Stepien 1996:259-260). The school results in this study showed that learners increased their achievement in terms of knowledge acquisition from the pre- to the post-test significantly. However, no attempt was made to compare the effectiveness of the problem-based teaching strategies used by the student teachers with alternative strategies that may have produced similar results.

However, qualitative results showed that some of the prospective teachers were not fully prepared by their problem-based training to manage learning in cooperative groups and to act out their new roles as learning facilitators. This can be expected if the training is short, but the situation might have been less positive if the student teachers had to teach in a way they were not taught themselves (Hargreaves 2002:1). The following quotation illustrates the problem: "I know that I am a facilitator who is not supposed to transfer answers to them, but sometimes I felt like doing it". One below-average achiever $(40 \%)$ in this teacher's class reflected from the learners' perspective a need for more direct assistance, which the student teacher also sensed but did not know how to handle. Often when confronted with similar difficult situations teachers may easily slip back to what they know and what gives them security, that is, talk-and-chalk (Richards \& Killen 1993). These student teachers did not slip back to a talk-and-chalk methodology but did not know what to do either when learners really had a breakdown in 
the learning process. Two had the limited view that once they had designed a problem-solving task, their role as facilitator entailed functions such as reflective questioning, motivation and emotional support only. This view may have developed because in their university-based training the student teachers were able to provide one another with considerable support. They were also operating from a strong knowledge base (all had science degrees). These two factors meant that the lecturer did not need to provide these learners with forms of direct assistance that were sought by some of the school learners.

When supervising cooperative work, Killen (2000) mentions that a facilitator can wear several hats varying from that of discussion leader, consultant and counsellor to tutor. While the prospective teachers were mostly successful with the first three, the tutor role was completely neglected. Within a learner-centred strategy, the tutor role is appropriate when a "group is not making adequate progress" (Killen 2000:75). A tutor may explain things, give additional information, or simply answer the learners' questions. A facilitator is responsible not only for initiating the learning, but also to "ensure the maintenance of learning within the framework of the problem setting" (Slabbert 1996:93). This is a very delicate diagnosis that all teachers will have to make before adopting a particular teaching strategy in problem-solving. If a facilitator intervenes too soon though, learners will be deprived of an opportunity to search their internal and external resources, which could have placed them on a higher level of intellectual empowerment. Teachers need to be extremely flexible in their facilitation skills. When problem-solving is used they need to make momentto-moment decisions depending on the situation, since problem-solving is less structured and learner behaviour therefore less predictable than direct instruction.

This result implies that the training programme needs to focus intentionally on developing competencies associated with the tutor role when facilitating learning in complex classrooms where learners have a variety of abilities, learning styles, levels of prior knowledge and self-esteem. These results serve as signposts as to where the strengths and weaknesses of this methodology course lie, which could not have been anticipated during the initial design phases of the problem-solving curriculum framework.

\section{CONCLUDING REMARKS}

The teacher training intervention described in this article attempted to address the problem of how to make sure that constructivist, learner-centred pedagogy is transformed into the ability to transfer and use it in complex real classrooms. If this does not happen, Technology will just be another "dead subject", as one student teacher warned us. The results reported in this article provide evidence that engaging trainee Technology teachers in realistic problem-solving activities can have two direct benefits. First, it can assist them to develop their own understanding of Technology. Second, it can provide them with sufficient pedagogical knowledge to apply the problem-solving strategy in real classroom situations with reasonable success.

However, facilitating learning in a problem-based environment, and using cooperative learning, demand competence on the part of the facilitator to ensure that learning is meaningful for all learners. The future Technology teacher education programme will have to pay more attention to preparing prospective teachers for coping with the real learning needs of particular learners. A competent facilitator is attentive to academic and social interactions and is skilled in maximising task and process aspects of group discussions towards the intended outcomes (Wilkerson \& Gijselaers 1996). In a less predictable learnercentred environment facilitators have to "think on their feet" to make the best decisions in an attempt to optimise the learning process for all learners. It was evident in this study that beginning teachers need both experience with learning through problemsolving and direct guidance in the application of this strategy in order to use it effectively in their own teaching.

\section{REFERENCES}

Albanese, M A \& Mitchell, S 1993. Problem-based learning: a review of literature on its outcomes and implementation issues. Academic Medicine 68(1):52-68.

Barrows, H S 1986. A taxonomy of problem-based learning methods. Medical Education 20:481-486.

Barrows, H S \& Tamblyn R N 1980. Problem-based learning: an approach to medical education. New York: Springer.

Black, P \& Atkin, J M (eds) 1996. Changing the subject. Innovations in science, mathematics and technology education. OECD. London/Paris: Routledge.

Boud, P \& Feletti, G 1997. The challenge of problem-based learning (2nd ed.). London: Kogan Page.

Claxton, G 1999. Wise up: the challenge of lifelong learning. London: Bloomsbury Publishing. 
DoE 1996. Technology 2005 Draft National Framework for Curriculum Development. The HEDCOM Technology Education Project. Pretoria.

DoE 1997. Curriculum 2005 for Grade 1-9. Government Gazette no 18051. Pretoria: Government Printer.

DoE 2000a. Curriculum 2005 Review Report. A South African curriculum for the Twenty First Century. Online available from: (http://education.pwv.gov.za/Policies\%20and\%20Reports/2000_Reports/2005/Chisholm)

DoE 2000b. The norms and standards for educators. Government Gazette no 20844. Pretoria: Government Printer.

Duch, B J, Groh, S E \& Allen, E A 2001. The power of problem-based learning. Virginia: Stylus Publishing.

Eason, PR \& Green, D A 1987. Developing real problem-solving in the primary classroom, in Fisher, R (ed) Problem-solving in the primary classroom. Oxford: Basil Blackwell.

Everwijn, S E M, Bomers, G B J \& Knubben, J A 1993. Ability- or competence-based education: bridging the gap between knowledge acquisition and ability to apply. Higher Education 25:425-438.

Fish, D 1989. Learning through practice in initial teacher training. London: Kogan Page.

Gallagher, S A \& Stepien, W J 1996. Content acquisition in problem-based learning: depth versus breadth in American Studies. Journal for the Educational Gifted 19(3):257-275.

Hargreaves, A 2002. Four ages of professionalism and professional learning. Gauteng Institute for Educational Development Conference. February 2002: Pretoria.

HEDCOM 1996. The HEDCOM Project: Technology 2005. Department of Education: Pretoria.

Herschbach, D R 1995. Technology as knowledge: implications for instruction. Journal of Technology Education 7(1):113-19

Jansen, J D 1997. "Essential alterations?" A critical analysis of the states syllabus revision process. Perspectives in Education 17(2):1-1.

Kahn, M J \& Volmink, J D 1997. A position paper on technology education in South Africa. Commissioned by the Development Bank of South Africa. Houghton: Edunet Consultants.

Killen, R 2000. Teaching strategies for outcomes-based education. Lansdowne: Juta.

King, A 1993. "From sage on the stage to guide on the side". College Teaching 41(1):3035.

Luckett, K 2001. A proposal for an epistemically diverse curriculum for South African higher education in the $21 \mathrm{st}$ century. South African Journal of Higher Education 15(2):49-61.

Ornstein A C \& Hunkins F 1993. Curriculum: foundations, principles and theory. (2nd edition). Needham Heights: Allyn \& Bacon.

Richards, C \& Killen, R 1993. Problems of beginning teachers: perceptions of preservice music teachers. Research Studies in Music Education 1(1):40-51.

SAQA 1997. Proceedings and decisions of SAQA. South African Qualifications Authority Bulletin 1 (1) May/June 1997:1-20.

Schmidt, H G 1983. Problem-based learning: Rationale and description. Medical Education 17:11-6.

Schmidt, H G 1993. Foundations of problem-based learning: some explanatory notes. Medical Education 27:422432.

Schön, D 1987. The reflective practitioner. New York: Basic Books.

Slabbert, J A 1996. Maximising human potential through facilitating lifelong learning. Manuscript for publication by the HSRC: Pretoria.

Spady, W G 1994. Outcomes-based education: critical issues and answers. American Association for School Administrators: Arlington, VA.

Tanner, C K, Galis, S A \& Pajak, E 1997. Problem-based learning in advanced preparation of educational leaders. Educational Planning 10(3):3-12.

Thomas, T 1988. Studies in design education, craft and technology. Technological Education and Science in School Winter $21(4): 12-14$.

Van Loggerenberg. A 2000. Implementing a problem-based learning model in the training of teachers for an outcomes-based technology curriculum. PhD Dissertation. University of Pretoria: Pretoria.

Waks, S 1993. Technology curriculum in South Africa 1993: aspirations, implementation and a proposal for an operational methodology. Johannesburg: Abel.

Wilkerson, L \& Gijselaers, W H 1996. Bringing problem-based learning to higher education: theory and practice. New directions for teaching and learning Winter 68:13-21.

Williams, A \& Williams, P J 1997. Problem-based learning: an appropriate methodology for technology education. Research in Science \& Technological Education 15(1):91-103.

Whittle, P (ed) 1993. Innovative ideas and techniques for science educators in Africa. International Council of Scientific Unions: International Centre for Conservation Education. 